\title{
TRAUMATIC SUBDURAL EFFUSIONS
}

BY

\section{A. A. McCONNELL}

(RECEIVED 20TH NOVEMBER, 1941)

Penfield (1924) first used the term " effusion" applied to fluid in the subdural space, and Naffziger (1924) was the first to draw attention to subdural accumulations of fluid in acute head injuries. In an earlier paper the former (Penfield, 1923) had demonstrated that the amount of fluid in the space varied from a few drops to $1 \mathrm{c.cm}$. in a dog of 5 kilogrammes. There is no publication dealing with the normal amount of subdural fluid in the human being or with its constitution. Observations at operation on non-traumatic cases suggest that the amount of fluid normally present is not sufficient to envelop the cerebral hemispheres; the operative field is usually the highest area of the skull, and when the dura is opened there is no obvious collection of subdural fluid and no overflow. When, however, the dura at the base of the brain is opened with the patient's head erect, as in the temporal approach to the gasserian ganglion, a considerable amount of fluid can be obtained without incising the arachnoid membrane. It would seem that the fluid indigenous to the subdural space is free and tends to accumulate in the dependent parts of that space. Subdural fluid may be deemed to be in excess: $(a)$ when it spurts or flows through an opening in the dura at the highest part of the skull; $(b)$ when the escape of fluid leaves the brain obviously depressed; or $(c)$ when the escape of fluid is followed by free pulsation of a brain in which pulsation has been absent. Sometimes the brain engages in the dural opening and does not pulsate, thus giving the impression of cerebral œdema, but the passage of a spatula under the dural edge releases fluid and the brain falls away and begins to pulsate freely. When there is a bilateral excess of fluid there does not appear to be any communication between the two sides; each demands a separate opening. Occasionally a definite excess of fluid may be found over one part of a hemisphere and none over another part of the same hemisphere. The term "subdural hydroma" has been given to these apparently encysted collections of subdural fluid.

It is easier to demonstrate an excess of subdural fluid in the living than in the dead subject, for unless a premeditated search be made for it at autopsy, the fluid may escape during the examination, and, unlike blood, leave no trace of its former presence; the pathologist merely remarks, "A lot of fluid seems to be present."

Excessive amounts of fluid have been found in the subdural space soon or some time after a head injury in 30 cases. These cases fall into four groups. 
Group 1.-Patients whose condition was deteriorating, usually within 48 hours of the accident (8 cases).

Group 2.-Patients who were in the process of recovery from definite general cerebral contusion, but in whom full recovery seemed to have been checked.

Group 3.-Patients suffering from headache, dizziness, and vague symptoms of nervous instability dating from a head injury.

Group 4.- Patients in whom headache and occasionally some definite nervous system, constant for the individual, started some time after a head injury.

Case reports illustrative of each of these types will be given.

Group 1.-Patients whose condition was deteriorating, usually within 48 hours of the accident ( 8 cases).

Case 1.-A. N., male, aged 30, was arrested after a street fight, and spent the night in prison. Next morning he was found to be drowsy, slow in answering, and the pulse rate was 50. There was a small scalp wound on the right side. No focal signs could be found. On the diagnosis of extradural hæmorrhage an opening was made in the right temporal region. There was no blood outside the dura, but when the latter was opened a large quantity of clear fluid under great tension rushed out, leaving the brain depressed for more than a centimetre. The patient made a rapid and complete recovery. He remembered every detail of the fight and the blow on the head.

Case 2.-M. E., female, aged 14 months. Admitted 20th September, 1934.

Two days before admission the baby, when trying to walk, fell. The parents did not think that she was hurt as she immediately resumed her attempts to walk. Next day the movements of the left hand appeared weak, and the day after both left arm and leg were paretic. She became quiet and listless and did not cry. On admission she noticed what was going on about her. The left limbs were flaccid and showed no spontaneous movement; Babinski reflex positive on the left; the left side of the face was weak.

An opening was made above the right temporal region. When the dura was opened a large amount of clear fluid escaped and the brain expanded. 22nd September. Some spontaneous movement of the limbs, later, recovery. 3rd October. Discharged.

These two cases may be regarded as examples of pure expanding lesions, as there was no evidence of initial concussion. In the next six cases the subdural fluid was associated with general cerebral contusion.

Case 3.-K. J., male, aged 58, slipped in the street and fell on the back of his head on 19th July, 1940. He was dazed and the police brought him to a Dublin hospital at 12.30 p.m. A small scalp wound in the occipital region was dressed. There were no indications of intracranial injury, but the patient was kept in for the night and discharged next morning apparently well.

Next day at 5 p.m., after a "lucid interval" of 29 hours, he suddenly became unconscious, was taken back to hospital and later transferred to the Richmond Hospital. On examination. Comatose, did not react to painful stimuli. Pupils equal and reacted to light. The right side of the mouth seemed to sag. There was tone in all limbs and there was no Babinski reflex. Blood pressure 120/60; pulse 88; respirations 36 ; temperature $99.8^{\circ} \mathrm{F}$. Fifteen ounces of urine were withdrawn by catheter, sp. gr. 1010, no abnormal constituents. Blood urea $91 \mathrm{mgm}$. per $100 \mathrm{c.cm}$.

An opening was made in the left temporal region. When the dura was nicked a jet of fluid shot up several inches; complete opening allowed a large quantity of 
fluid to pour out. The brain was not pulsating and it remained about $1 \mathrm{~cm}$. deep to the dura. A spatula passed into the subdural space gave the impression that the hemisphere was too small for the skull. An area of hæmorrhage about $1 \mathrm{~cm}$. in diameter was noted on the surface of the temporal lobe.

A similar opening was made in the right temporal region and the dura opened. There was no subdural fluid but the brain was retracted about $1 \mathrm{~cm}$. It appeared normal but did not pulsate. These operations did not influence the patient's condition in the slightest. 22nd July. Generalized fits, controlled by $1 \mathrm{c.cm}$. luminal. Lumbar puncture, normal fluid and normal pressure. Blood pressure 160/90. He died next day.

Post-mortem examination revealed gross general arteriosclerosis, the basilar, carotid, and coronary arteries being veritable "pipe-stems." The brain did not appear as retracted in death as in life and no lesion was found, apart from the arteriosclerosis.

Case 4.-C. J., aged 42, was admitted to a Dublin hospital shortly after a motor accident on 22nd July, 1939. He walked into hospital; he spoke sensibly, but seemed rather dazed. A scalp wound in the left occipital region was stitched. Next day. He was still rather dazed and talked erratically, but physical examination was negative and he was allowed to go home.

25th July. Re-admitted. He could speak, and understand what was said to him, making slow but intelligent answers. The left side of the face and the left arm were paretic; the left leg was weaker than the right and there was a positive Babinski on the left side. Pulse 86. A diagnosis of epidural or subdural hæmorrhage was made.

Operation. Local anæsthetic. When the needle was inserted he became very excited and had to be held on the table. An opening was made in the right temporal region, exposing a normal dura, which, however, did not pulsate. When the dura was opened there was a gush of slightly blood-stained fluid with a few small clots. A large quantity of fluid escaped. The brain appeared normal. It began to pulsate, but it remained two centimetres below the level of the dura. The intention had been to open both sides of the head, but the patient's excitement had not abated, and it was argued that the operative findings explained the symptoms. The wound was drained with rubber tissue.

26th July. More difficulty in answering questions. Very restless.

27 th July. More drowsy. Complete left hemiplegia. The wound was re-opened, but no fluid was obtained; the rubber tissue was removed. An opening in the left temporal region was made, and exactly the same condition found as at the first operation- $\mathbf{a}$ rush, then a copious outflow, of slightly blood-stained fluid. After a transitory improvement the patient became worse; first delirious, then deeply comatose. Drainage ceased, and the rubber tissue was removed. Within the next four days the wounds were re-opened twice and quantities of clear fluid escaped. After that no more fluid was obtained, but the brain was shrunken. Intravenous injections of glucose were given.

A week after the second operation the patient began to react and was able to drink, but he did not become conscious of his surroundings till the seventeenth day, when he began to move his left arm. From this date recovery was uneventful. There was complete amnesia for the accident and most of his stay in hospital.

On 17th March, 1940, his wife reported that he had had a fit, in which his left side "worked." Two days later examination showed a slight relative weakness of the left arm and left leg. The patient said that he felt weak and nervous but was otherwise well.

Case 5.-F. M., male, aged 26, admitted 30th August, 1937.

At 11 p.m. on 29th August the patient collided with another cyclist and was 
thrown to the ground. He was brought unconscious to a County hospital. Pulse 83; temperature $97^{\circ} \mathrm{F}$; pupils equal and reacting; scalp wound $3 \mathrm{in}$. long in left frontal region. Next morning he could be partially roused by painful stimulation. Pulse 68 to 52 . Next day at 11 p.m. he was very drowsy, but could be wakened and induced to answer questions. Pulse 48. Pupils dilated, equal, and reacted to light. There was relative weakness of the right side of the mouth, the right arm, and the right leg. There was a Babinski sign on the right foot.

Operation. Local anæsthetic. The scalp wound was excised and closed. An opening was made in the left temporal region. The dura was tense and not pulsating. When it was incised there was a rush of clear fluid under tension. A large amount escaped, and the brain was then seen to pulsate normally and rise to dural level. Pulse rate was now 70 .

Recovery was uneventful and complete.

Case 6.-O'T. P., aged 48, admitted 8th August, 1940.

Ten days before admission he fell off a horse and was immediately unconscious. There was some bleeding from the ears and nose at the time. The right pupil was dilated, but reacted to light, and he had a grasp reflex in both hands. Lumbar puncture, pressure $100 \mathrm{~mm}$., fluid blood-stained.

8th August, 4.30 p.m. Semi-comatose, reacted slightly to painful stimuli. Pulse 100 ; temperature $98 \cdot 8^{\circ} \mathrm{F}$., moving arms and legs; grasp reflex both hands. Lumbar puncture. Fluid did not rise in manometer; yellow tint; protein 0.04 per cent., cells 4 per mm. 3 c.cm. removed. Blood pressure 120/80. At 9 p.m. on supraorbital pressure the right side of the face alone reacted. The right hand grasped the sheet firmly; the left was passive.

Next day he was deeply unconscious. Pulse 140 ; temperature $102^{\circ}$ F.; respirations 60. Pupils moderate and equal, but the left did not react to light. Some tone in right arm; none in left. Blood pressure 90/75.

A drill hole was made in the right temporal region. A nick in the dura released fluid under tension. A needle was passed through the opening and $30 \mathrm{c.cm}$. of dark yellow fluid was aspirated. The opening was enlarged and considerably more fluid escaped. The brain, which did not pulsate, lay $1 \frac{1}{2}$ centimetres from the dural level. The protein content of the fluid was 0.18 per cent. A similar opening was made on the left side. A smaller amount of fluid was obtained and the brain was retracted about $\frac{1}{2}$ centimetre. Blood pressure remained at 90/75.

The operation did no good, and the patient died 4 hours later.

Post mortem. A considerable amount of fluid under scalp in region of right opening. Posterior fossa normal; no blood or excess of fluid. Dura slack; brain shrunken. When the brain was removed this shrinkage could not be appreciated, nor could the amount of fluid still present be estimated. On the lateral posterior aspect of the right orbital surface there was a linear laceration about $3 \mathrm{~mm}$. deep. On the lateral surface of the right temporal lobe, just behind the tip of the temporal pole, was an area $2 \mathrm{~cm}$. in diameter of subarachnoid hæmorrhage overlying a shallow laceration.

In the first two cases there was no evidence of cerebral injury, and it would appear that subdural fluid accumulated rapidly and produced the deterioration in consciousness and the focal signs in the same manner as these phenomena are produced by a progressive hæmorrhage. In the next six cases cerebral damage was immediate, and later subdural fluid accumulated sufficiently to modify the clinical picture. The fatality in Case 3 may be attributed to compression by the fluid, though the role of the arteriosclerosis must be considered; in the other fatal cases cerebral damage was probably more responsible. 
These cases were in most respects similar to those of intracranial hæmorrhage, and it does not seem possible to make a differential diagnosis. Hæmorrhage and accumulations of subdural fluid may be classified together as " traumatic expanding lesions."

The eight cases of Group I are summarized below.

Table 1.-Group I. Subdural Fluid acting as an Expanding Lesion

\begin{tabular}{|c|c|c|c|}
\hline COURSE OF CONSCIOUSNESS & ONSET OF FOCAL SIGNS & PULSE-RATE & RESULT \\
\hline $\begin{array}{l}\text { 1. Became drowsy } 12 \text { hours } \\
\text { after injury } \ldots \\
\text { 2. Listless } 24 \text { hours after injury } \\
\text { 3. Concussion; lucid interval } \\
\text { of } 29 \text { hours. Coma .. } \\
\text { 4. Concussion to automatism } \\
\text { 5. Concussion to accessibility } \\
\text { 6. Concussion to semicoma .. } \\
\text { 7. Concussion to semicoma .. } \\
\text { 8. Comatose since injury }\end{array}$ & $\begin{array}{l}\text { None. } \\
\text { Hemiparesis } 48 \text { hours. } \\
\text { Facial weakness } 29 \text { hours. } \\
\text { Hemiparesis } 4 \text { days. } \\
\text { Hemiparesis } 24 \text { hours. } \\
\text { Babinski and facial weak- } \\
\text { ness immediate. } \\
\text { Hemiparesis } 48 \text { hours. } \\
\text { Hemiplegia } 11 \text { days. } \\
\text { Bilateral rigidity. } \\
\text { Babinski } 27 \text { hours. }\end{array}$ & $\begin{array}{c}50 \\
110 \\
88 \\
86 \\
68 \text { to } 48 \\
100 \text { to } 140\end{array}$ & $\begin{array}{l}\text { Recovered. } \\
\text { Recovered. } \\
\text { Died. } \\
\text { Recovered. } \\
\text { Recovered. } \\
\text { Died. }\end{array}$ \\
\hline
\end{tabular}

Group 2.-Patients who were in the process of recovery from definite general cerebral contusion, but in whom full recovery seemed to have been checked.

Case 7.-S. P., male, aged 22, admitted 22nd January, 1930. Referred by Mr. J. F. O'Connor, F.R.C.S.I., Limerick.

20th November, 1929. The patient fell off the back of a motor car. His head hit the ground and he became unconscious immediately. He was brought to the County hospital, where he remained stuporous for ten days, but another fortnight passed before he was able to answer simple questions intelligently. He remained mentally confused and irritable. No neurological signs were discovered. The pulse rate hovered between 40 and 50 for three weeks. As the mental state was getting worse he was transferred to the Richmond Hospital.

22nd January, 1930. The patient was very excitable and said that he never felt better in his life. He did not understand why he had been sent to Dublin and he demanded immediate discharge. There was great difficulty in controlling him, in spite of bromides and hyoscine. He talked freely, but it was obvious that his memory for recent events was defective and that his talk had little relation to reality. Pulse rate 80 to 100 .

The then neurologist and the psychiatrist agreed that the case was one of dementia and that it was doubtful if the injury had much to do with the mental condition. They advised immediate certification and removal to an asylum.

Radiographic examination, however, had revealed a stellate fracture of the right parietal bone, with a fissure traversing the line of the middle meningeal artery, and the 1 ight pupil, though reacting, was larger than the left. It was therefore decided to do an exploratory operation before certification. 25th January. General anæsthesia. An opening was made in the right temporal region. There was no epidural hæmorrhage. When the dura was opened a considerable amount of blood-stained fluid escaped. The brain lay well below dural level and did not expand. There was some excess of subarachnoid fluid, which gave the brain a watery appearance. He at once became amenable and more rational.

On the fourth postoperative day he could remember events up to the accident, 
understood where he was and why. Felt well. From this date recovery was uninterrupted and the patient was discharged on 5th February. Mr. O'Connor wrote in July 1941 that the patient had remained well and seemed quite normal.

Case 8.-Y. T., male, aged 40, admitted to Richmond Hospital, Dublin, 10th August, 1940.

On 2nd August he fell, the back of his head hit the ground, and he became comatose immediately. After admission to a local hospital he passed into delirium, which continued for seven days.

10th August. Examination: the patient was quiet; he would not answer questions, but talked incessantly and incoherently. Pulse 50; blood pressure 150/80; no neurological signs. 13th August. Still mentally confused, repeating phrases over and over again. Answered the same questions differently each time. Inclined to make jokes. When asked "Where are you?" he answered, "I'm here." "What age are you?" "I'm old enough to know better." He could go to the lavatory by himself. Pulse 50 .

Operation. Local anæsthesia. Patient co-operative. An opening was made in the skull just behind the hair line in the right frontal area. When the dura was opened the brain was close up to it and did not pulsate. A spatula passed under the dura released a very small amount of subdural fluid from the parietal region.

A similar opening was made on the left side. A nick in the dura released yellowbrown fluid under tension. The nozzle of a syringe was put into the opening and $10 \mathrm{c.cm}$. of the fluid was collected. The opening was enlarged and there was a further rush of fluid. The brain appeared normal and lay $1 \mathrm{~cm}$. deep to the dura; it did not pulsate. A piece of thin rubber was inserted as a drain. Immediately after the operation the pulse rate was 48; an hour later it rose to 70. 14th August. Quiet. Less confused. Pulse rate 84 . Two days later he was able to be out of bed, knew where he was, answered intelligently. Pulse 80. 20th August. Recovery complete.

The fluid had a protein content of 3.5 per cent.

Case 9.-Q. T., male, aged 54, admitted 7th November, 1940.

Three weeks before admission the patient fell off a bicycle. He was deeply comatose for 24 hours, when he became delirious.

Examination: he was confused and incoherent but could obey commands. He did not know where he was. The tongue was dry. Pulse 80; heart rate irregular 130; extra systoles; hard arteries; blood pressure 120/70; respirations 32 ; temperature $101^{\circ} \mathrm{F}$. Dullness at bases of both lungs. Pupils equal and reacted to light. Limitation of upward gaze left eye. Ptosis of left eyelid. Left facial weakness. Hoffman reflex in left hand. Plantar responses flexor. A line of fracture could be felt extending from the left frontal region to below and behind the left parietal eminence. Fluids were administered. 8th November. Less confused; he could answer questions. Blood urea $90 \mathrm{mg}$.

Operation. Local anæsthesia. An opening was made above the fracture on the left side, and a large quantity of slightly turbid subdural fluid escaped. The brain did not expand and remained at a depth of $1 \frac{1}{2} \mathrm{~cm}$. A drain was placed under the dura and brought out through the wound. A similar opening was made on the right side; there was no subdural fluid, and the brain was retracted about $1 \mathrm{~cm}$., but began to expand and pulsated freely, coming up to dural level. A spatula passed between the dura and the brain did not reveal any lesion or any collection of fluid or blood. This wound was closed without drainage.

Next day he was quite conscious and coherent, but did not remember coming to hospital. Heart rate 110, but extra systole every third beat, hence pulse 74 . Breathing shallow; passive congestion of lungs; respirations 36 ; temperature $101 \cdot 5^{\circ} \mathrm{F}$. The drain was partially withdrawn and a large amount of fluid escaped. For the next 
three days his mental condition improved, but hypostatic pneumonia developed. 5th November. Mors.

Autopsy. No subdural fluid demonstrated. Brain shrunken, no sign of any lesion on surface or on section.

Case 10.-M. P., male, aged 12, admitted 28th December, 1940, at 7 p.m.

He had been knocked off a bicycle at 4 p.m. that day. He was unconscious for about an hour. On admission he was able to speak sensibly but next morning he did not remember coming into hospital. Pulse 75; blood pressure 105/75; no neurological signs. Next day he felt well. Lumbar puncture, pressure $120 \mathrm{~mm}$. of water. The patient's course was satisfactory in every way. The pulse rate dropped occasionally to 64 . A week later he complained of right frontal headache, but next day he did not remember that he had a headache yesterday.

8th January. Severe headache. Lumbar puncture, pressure $180 \mathrm{~mm}$. of water. Pulse 60 . The headache was not relieved by the lumbar puncture.

Operation. Right temporal opening. Dura not pulsating. When it was opened a large quantity of clear fluid spurted out, and carried with it at the end some minute clots of blood. The brain lay well below the dura, but began to pulsate in a few minutes and rose to dural level when the boy held his breath or coughed.

Left temporal opening, similar findings but no sign of blood clot.

9th January. Mild headache. Pulse rate 65 . Lumbar puncture, pressure $85 \mathrm{~mm}$. of water. Fluids forced. The patient was quite comfortable for the next three days but the pulse rate remained about or below 60 .

14th January. Pulse 50. Headache. As the boy had been taking fluids freely and the blood pressure was constant, the wound on the left side was re-opened in search of re-accumulation of fluid. No fluid was present; the brain was shrunken and pulsating freely. A continuous drip (intravenous) of 5 per cent. glucose was given. From this point onwards the patient had no headache. The pulse rate remained about 60 for four days, and on 17th there were several attacks of vomiting. 19th January. Pulse rate rose to 80 and recovery was uninterrupted and complete.

The delay in recovery after operation was probably due to delay in administering a sufficient quantity of fluid.

These cases are summarized in Table 2.

TAble 2.-Group II. Subdural Fluid during Recovery from Contusion

\begin{tabular}{|c|c|c|c|c|c|}
\hline No. & $\begin{array}{l}\text { TIME AFTER } \\
\text { CONTUSION }\end{array}$ & MENTAL STATE AND SYMPTOMS & PULSE RATE & $\begin{array}{l}\text { LINEAR } \\
\text { FRACTURE }\end{array}$ & RESULT \\
\hline $\begin{array}{l}1 \\
2 \\
3\end{array}$ & $\begin{array}{l}2 \text { months } \\
10 \text { days } \\
3 \text { weeks }\end{array}$ & $\begin{array}{l}\text { Traumatic dementia } \\
\text { Confusion, moderate } \\
\text { Confusion, moderate (hypo- }\end{array}$ & $\begin{array}{c}40 \rightarrow 80 \\
50 \\
80\end{array}$ & $\frac{+}{+}$ & $\begin{array}{c}\text { Good } \\
\text { Good } \\
\text { Died }\end{array}$ \\
\hline $\begin{array}{l}4 \\
5 \\
6\end{array}$ & $\begin{array}{r}11 \text { days } \\
8 \text { days } \\
12 \text { days }\end{array}$ & $\begin{array}{l}\text { Confusion, mild headache } \\
\text { Clear, headache } \\
\text { Clear, headache }\end{array}$ & $\begin{array}{c}60 \\
60 \\
60 \\
\text { (L.P. pressure, } \\
180 \mathrm{~mm} . \mathrm{H}_{2} \mathrm{O} \text { ) }\end{array}$ & $\begin{array}{l}+ \\
+ \\
-\end{array}$ & $\begin{array}{l}\text { Good } \\
\text { Good } \\
\text { Good }\end{array}$ \\
\hline
\end{tabular}

\section{Comment}

The only clinical feature common to all the cases was a halt at some stage of recovery, the patients remaining in some degree of confusion or suffering 
from severe headache. One patient died from hypostatic pneumonia, but in the other five cases progress to recovery was resumed immediately after removal of the subdural fluid.

The patient with pneumonia had a pulse rate of 80 and a heart rate of 130 on admission ten days after the injury; the other patients had or had had pulse rates between 40 and 60 . The rate increased immediately after removal of the fluid.

Lumbar puncture was performed in one case and gave a pressure of $180 \mathrm{~mm}$. of water. The tension of the fluid in these cases was not so great as in those of the first group, but the fluid flowed freely and in quantity in each case. In three of the cases the brain remained depressed after removal of the fluid.

These cases suggest that a halt in recovery from contusion associated with a low pulse rate may be due to the presence of subdural fluid, the fluid acting like a "wet blanket" and interfering with the full expansion of the brain which is necessary for the resolution of contusion.

The fact that the patients in this group were not getting worse suggests that the accumulation of subdural fluid had reached its maximum and had stopped. The condition may be classified as a passive " space-occupying " lesion in order to distinguish it from the active expanding lesion found in the patients of the first group. Intracranial hæmorrhage sometimes runs a similar course, and a diagnosis of a space-occupying lesion based on headache and a low pulse rate has led to the discovery of epidural hæmorrhage in one case and of subdural hæmorrhage in another.

Group 3.-Patients suffering from headache, dizziness, and vague symptoms of nervous instability dating from a head injury. 1939.

Case 11.-T. J., male, aged 40, admitted to the Richmond Hospital on 25th May,

On 28th July, 1938, he fell from a height of $15 \mathrm{ft}$., his head striking a concrete block. There was a small scalp wound and a depressed fracture of the right parietal bone. He was unconscious for some hours. During the twelve days of his stay in the local hospital he began to suffer from shooting pains in the head, brought on by "visions" of the fall, and occurring just when he was dropping off to sleep. Later the pain occurred more frequently, and was referred to the left parietal region. When he stooped or turned his head rapidly he became dizzy. He was generally nervous and said that he could not sleep.

26th May, 1939. Neurological examination was negative. Radiography showed a depressed fragment of bone about the size of a penny, its outer table being on a level with the inner table of the skull. Union had taken place.

It was thought probable that the dura had been injured at the time of the accident and that the patient's symptoms might be due to adhesions between it and the brain.

30th May. Operation. Local anæsthesia. A small flap was raised and the depressed bone removed. When the dura was opened a considerable quantity of clear fluid escaped and the brain began to pulsate freely. A flap of dura was raised; there were no adhesions, so the dura was closed and the bone replaced. A single burr hole was made in the left parietal region; there was no fluid and the brain lay $\frac{1}{4}$ in. below dural level.

The patient was delighted with the result of the operation. He was discharged 
on 12th June, and on 17th July was re-admitted complaining of soreness about the wound on the right side and dizziness on stooping. The wound was soundly healed, but the replaced bone was loose. He was kept three days in hospital, during which he slept well and made no complaints. He was then reassured and sent home. 28th November, 1939. He was re-admitted because of a discharging sinus in the wound. His symptoms were practically the same as they were on his first admission. 4th December. The bone which had been replaced was necrotic and was removed. He was well and cheerful all the time in hospital and was discharged on 15th December.

3rd July, 1940. Interviewed for insurance purposes. His symptoms were practically the same as when he was first seen. The defect in the skull had not added to them.

Case 12.-M. P., seaman, aged 28, admitted 28th May, 1940.

On 14th February, 1936, he fell about twenty feet on to an iron deck. He was unconscious for a week, and for the first two days violent and delirious. He was then admitted to an Australian hospital and kept for $3 \frac{1}{2}$ months. During this time he complained of severe headache, and periods of violence alternated with states of lethargy and sullenness. Improvement was slow, but in May of that year he was sufficiently recovered to return to England.

From this time until admission he complained of headache, poor memory, and dizziness, and frequently stated that he was "finished for life." When in hospital he was sensible and amenable, and it was thought that the headache was genuine. Neurological examination was negative.

Encephalography was discarded because of the attendant discomfort, and the patient agreed to exploratory openings being made in the skull.

30th May, 1940. Operation. An opening was made on the left frontal region. There was a considerable amount of subdural fluid, and when it was removed the brain pulsated more freely; but there also seemed to be an excessive amount of subarachnoid fluid, which suggested that there was a certain amount of cortical atrophy on that side of the brain. A similar opening was made on the right side, but there was less fluid.

Next day the headache was completely relieved.

5th June. Discharged. No headache since operation.

August 1940. A letter was received from his sister: "I cannot say that I see any improvement; he is still irritable and cross at times." Headache was not mentioned.

The cases of group 3 are summarized in Table 3.

TABLE 3.-Group III

\begin{tabular}{|c|c|c|c|c|}
\hline NO. & CONTUSION & SYMPTOMS & ONSET & $\begin{array}{c}\text { TIME ELAPSED } \\
\text { BETWEEN OPERATION } \\
\text { AND INJURY }\end{array}$ \\
\hline $\begin{array}{l}1 \\
2 \\
3 \\
4\end{array}$ & $\begin{array}{l}+ \\
+ \\
+ \\
+\end{array}$ & $\begin{array}{l}\text { Headache, dizziness, } \\
\text { nervous instability } \\
\text { do. } \\
\text { do. } \\
\text { Headache, poor vision, } \\
\text { nervous instability }\end{array}$ & $\begin{array}{l}\text { Immediately after } \\
\text { recovery } \\
\text { do. } \\
\text { do. } \\
\text { do. }\end{array}$ & $\begin{array}{l}1 \text { year } \\
4 \text { years } \\
3 \frac{1}{2} \text { months } \\
7 \text { months }\end{array}$ \\
\hline
\end{tabular}

\section{Comment}

The patients in this group afforded typical examples of the " post-traumatic syndrome" of headache, dizziness, and nervous instability, all had suffered 
initial concussion. The impression gained at operation was of a shrunken atrophic brain, with an excess of fluid, both subdural and subarachnoid; there was no tension. The patients stated that the headache had been relieved by the operation, but it was obvious that the nervousness was not diminished, nor were the complaints of dizziness less frequent.

A review of these cases suggests that the post-traumatic syndrome is due to intrinsic cerebral damage inflicted at the moment of the accident. It is possible, however, that the accumulations of fluid may have played a part by preventing the brain from reacting normally to injury. Removal of fluid during the acute stage might have been beneficial, but removal of fluid a long time after the injury could not be expected to improve the condition of the brain. For this reason no further cases of the true post-traumatic syndrome have been submitted to operation.

Group 4.-Patients in whom headache and occasionally some definite nervous symptom, constant for the individual, started some time after a head injury.

The results of operation in this group were better than in any of the others.

Case 13.- R. D., female, aged 20, admitted to Richmond Hospital, Dublin, 18th April, 1940, on account of left frontal headache.

In the beginning of January 1940 she fell off a toboggan and her head struck the ground. She got up immediately. Apart from a momentary sensation of dizziness she felt quite well and only mentioned the fall when directly questioned. At a dance that night she "felt a bit shaky".

12th April, 1940. She began to complain of an ache all over the head. Two days later the headache became very severe and was confined to the left side; it was throbbing in character.

Examination a week later revealed slight lower facial weakness on the right side, the reflexes of the right leg were slightly increased. There was no Babinski. The pulse rate dropped occasionally to 60 . The fundi were normal. The diagnosis of a left frontal subdural hæmatoma was considered.

23rd April. Operation. Local anæsthesia. A small opening was made just behind the hair line in the left frontal region. The dura did not pulsate. When it was opened clear fluid welled up, and more escaped when the spatula was introduced. The brain then began to pulsate freely. Another opening was made in the right posterior parietal region, with similar findings. The headache was relieved and the facial weakness disappeared, but in the course of the next three days the headache returned and the patient became rather drowsy.

27th April. A right frontal opening was made and a larger amount of fluid obtained than from either of the previous openings. Several small clots came away in the fluid. A needle was passed into the right ventricle. There was no tension and the ventriculograms were normal. After this, recovery was uninterrupted and the patient was discharged on 13th May.

She continues free from symptoms.

Case 14.-A. P., male, aged 7, admitted to the Richmond Hospital on 26th January, 1939, because of epileptic attacks.

On the day before admission the boy had a generalized epileptic fit which lasted for three hours There was no warning of the attack. After it, he complained of severe pain in the left side of the head. In the early hours of 26th January he had what was described as a rigor, in which all his limbs were fixed in extension. $\mathrm{He}$ was admitted in a condition of status epilepticus, which was ultimately controlled by 
luminal. Neurological examination was entirely negative. On direct questioning the parents said that the boy had had a fall on the head " a month or two ago," but that he had not hurt himself as far as they knew. He had always been healthy.

28th January. Encephalography under avertin anæsthesia. The findings were inconclusive, so it was decided to perform ventriculography. For this purpose an opening was made behind the parietal eminence on the left side. When the dura was incised there was a rush of a large quantity of clear fluid under tension. The brain was retracted for about two centimetres and did not expand. The wound was closed.

After this the boy appeared to be perfectly well and there were no fits.

In the course of the next week a small swelling appeared at the site of the wound; it was thought to be a hæmatoma, but on 6th February a needle was passed into it and $20 \mathrm{c} . \mathrm{cm}$. of clear fluid was aspirated. The protein content of the fluid was $40 \mathrm{mg}$. per 100 c.c.m The fluid did not collect again and the boy was discharged on 26th February. He has continued well and free from attacks.

Case 15.-W. M., married woman, aged 58, admitted to Richmond Hospital on 17 th September, 1937, complaining of dizziness, headaches, and an overpowering inclination to sleep.

On 6th August, 1937, she slipped when coming downstairs and she thought that the back of her head struck one of the steps. She felt rather stupid for a moment but she resumed her work immediately. Apart from the attacks of dizziness she was well for nearly a month. Then, during a spasm of coughing, she felt a sharp pain shooting through her head from temple to temple. About the same time there was a sensation of "pins and needles" in both feet. She spent a fortnight in another hospital and had several lumbar punctures.

Examination: the medial aspects of both optic discs were slightly blurred. The only other abnormality was a Babinski reflex on the right side. A subdural hæmatoma was suspected.

18th September. Local anæsthesia. A left temporal opening exposed a tense brain which was not pulsating. A spatula was passed under the dura; clear fluid welled up from every direction, and in a minute or two pulsation of the brain was obvious. When a similar procedure was carried out on the right side fluid under tension escared when the dura was opened, and the brain did not pulsate until considerably more fluid was released by the spatula. Immediately before the release of fluid on this side the pulse rate was 64 ; immediately after, it was 80 . The patient felt better after these operations for 24 hours, but she then became gradually more drowsy and the pulse rate fell to 60 . It was thought that fluid had accumulated again, as the wounds had been closed without drainage. 21st September. Wound on right side opened. There was no fluid and the brain, which was pulsating, had dropped away from the dura for nearly a centimetre. The same condition was found when the left side was exposed. Large amounts of fluid were administered. The patient continued rather drowsy for the next two days, but then began to improve rapidly.

According to recent reports recovery was complete.

Case 16.-N. E., aged 33, admitted 26th January, 1941, on account of headache and occasional attacks of vomiting.

In 1937 the patient, who was captain of a well-known hurley team, was struck by a hurley stick just above the left ear. He was stunned for an instant but continued the game. There was no amnesia and no disability afterwards.

In 1939 the appendix was removed, and shortly afterwards he began to suffer from left-sided headaches. He felt " as though a swelling were moving about above the left ear." He complained of tiredness, unsteadiness, and inability to concentrate. 
Nausea was often present, and he had vomited about six times inside two years. He attributed all his troubles to the appendix operation.

On 10th January, 1941, he consulted Dr. Balfe, of Dublin, who found him giggling and laughing and emotionally unstable. General and neurological examination was negative, but radiograms of the skull disclosed large vascular channels and lacunæ in the region of the left coronal suture. These findings suggested the possibility of a meningioma, so the patient was admitted to hospital on 26th January. Next morning he walked out of hospital without telling anyone. Two days later he arrived at his home ninety miles distant, having walked the whole way according to his own statement. He had money in his pocket. He begged his people not to send him to hospital or to let anyone touch him.

This emotional storm soon subsided, but the headache continued and he was readmitted on 28th April for ventriculography. Neurological examination was negative.

30th April. A needle was passed into the right ventricle; the fluid pressure in the ventricle was $100 \mathrm{~mm}$. of water; $16 \mathrm{c.cm}$. of fluid were removed and replaced with air. The whole ventricular system appeared normal in the radiograms. An opening was then made in the left temporal region. When the dura was opened there was a gush of fluid from the subdural space, and later a free flow when a spatula was passed under the dura. The brain remained depressed. A piece of thin rubber was inserted as a drain.

After the operation the patient was encouraged to drink freely in order to promote expansion of the brain. During the next 24 hours enough fluid escaped to keep the inner layers of the dressing moist. The drain was then removed and the "waiting stitch" tied. The patient said that the headache was completely relieved.

7th May. Blood pressure remained constant at 138/88. The patient felt well. A careful record of the pulse rate was kept before and after the patient got up; it remained between 50 and 54. Atropine 1/50th gr. did not affect the rate.

9th May. The left temporal wound was re-opened. The brain was bulging into the opening; a spatula was passed but no fluid was found. The wound was closed and magnesium sulphate in hypertonic solution administered by rectum.

11th May. Pulse rate rose from 52 to 68 and, later, when patient got up the pulse rate rose from 66 to 78 . Blood pressure 120/80. From this date the pulse rate remained fairly steady between 74 and 84 , although it dropped to 54 on one occasion during the night.

25th May. Patient discharged, declaring himself well. From the date of the operation all the emotional symptoms, formerly so obvious, disappeared. A report on 30th June stated that he had resumed work and was perfectly normal.

1st September. The patient was re-admitted for observation. He was definitely psychoneurotic and subject to religious obsessions.

Case 17.-L. H., female, aged 32, employed in a cosmetic factory. Admitted 28th May, 1941, on account of severe headache.

On 1st February, 1941, the car in which the patient was a passenger collided with another car. The patient's head struck a pillar of the car and there was a slight abrasion in the right temporal region. The patient immediately said that she was all right, but in the course of an hour she collapsed and was taken to hospital. After another hour she awoke and insisted on leaving hospital. Next day she returned to work, but had to stop working in about half-an-hour because she felt so "shaky." She stayed in bed for a fortnight. On getting up she began to suffer from severe headaches in the right fronto-temporal region, which were increased by any activity or by stooping. She, however, went back to work, but found that she did "funny things," like giving silly orders, putting the wrong ingredients in cosmetics, or making mistakes in accounts. In April she was treated by dehydration methods for a month, but these produced no improvement. 
On admission. Neurological and radiological examination was negative.

29th May. Operation. An opening was made just above the junction of the anterior and middle thirds of the right temporal ridge. The anterior division of the middle meningeal artery crossed the opening. When the dura was opened the brain presented and there seemed to be a certain amount of fluid under the arachnoid. A spatula was passed forwards under the dura and a small amount of subdural fluid escaped. On passing the spatula downwards towards the temporal region fluid flowed freely. A strip of thin rubber was left as a drain in the subdural space.

The headache was completely relieved.

On the fifth day after operation the patient was sitting up, apparently very well, when she got a severe " neuralgic" pain in the region of the wound and fainted. Two hours later the pulse rate fell to 66 , but rose soon to its normal rate between 76 and 80. The neuralgic pain continued; it was quite different from the former headache. A week later the pulse rate dropped to 60 for some hours, and because of this and the pain, the wound was re-opened.

A definite adhesion was discovered between the arachnoid and the dura, just at the point where the meningeal artery lay. The slightest touch on the adhesion produced the intense neuralgic pain. The adhesion was divided and the pain disappeared immediately. There was no excess of subdural fluid. Amniotic membrane was tucked under the dura round the opening and the wound closed. Before the patient left the table it was decided to exclude subdural fluid on the opposite side, so an opening was made in the left frontal region just behind the hair line. An excessive amount of subdural fluid flowed out and pulsation of the brain became more marked.

The patient had an occasional slight headache for the next two days, but after that time recovery was complete. There has been no recurrence of symptoms.

25th July. Perfectly well. Complete amnesia for the accident and arrival in hospital.

Case 18.-C. J., male, aged 25, admitted to the Richmond Hospital on 4th January, 1940.

In March 1939 he was struck on the head by a falling tree. The roof of the left orbit was fractured and there was bleeding into the orbit and into the eyelids. He was unconscious for three days.

At the end of three weeks, on his discharge from another hospital, he was well except for a feeling of numbness and tenderness over the left side of the head. In July 1939 he began to complain of severe throbbing headaches, which came on at intervals varying from one to three days and lasting for two or three hours. These headaches were not modified by posture but were increased by effort of any sort.

Examination disclosed anosmia on the left side, but no other neurological symptoms. The patient was not nervous, nor did he seem to exaggerate his symptoms. He had no memory of the accident nor of events some hours before it. He welcomed the suggestion of an exploratory operation.

5th January, 1940. Operation. Local anæsthesia. A small burr hole was made just behind the hair line in the left frontal region. The dura was opened; the brain presented in the opening and did not pulsate. A narrow curved spatula was slipped between the dura and the arachnoid towards the frontal pole of the hemisphere. Clear fluid began to well up freely along the spatula. The flow continued steadily for some minutes. The spatula was then directed towards the temporal region and more fluid escaped. The brain was now pulsating freely. The wound was closed without drainage. From that moment to the time of writing the patient says that he has been free from headache and is quite fit for the work which he has resumed. The operation was done and his acknowledgment of complete relief registered before his claim for compensation was settled. 
Case 19.-L. D., male, aged 39, was conductor in a bus which, on 28th July, 1938, hit an electric light standard. His head struck the side of the bus and he became unconscious immediately. He remained unconscious for three days. Recovery was without incident and he was discharged from hospital on 15th September. He resumed work at the end of that month.

He was well for eight months; then he began to get attacks of headache and vomiting which would lay him up for three weeks at a time.

In February 1940 he began to feel that the left foot was turning outwards, but when he looked at it, it was stationary. Later, definite attacks occurred in which the left leg and left arm twitched and the left hand felt numb. Consciousness was lost in one of these attacks. From this time until his admission to the Richmond Hospital on 29th April, 1940, he had one fit, and the headaches continued.

30th April. There was slight unsteadiness in the movements of the left hand. The left limbs were slightly weaker than the right, otherwise neurological examination was negative. After a few days in hospital the patient felt well and decided to go out next day; but next day he was prostrate with intense headache and vomiting. This sequence recurred several times; he then accepted the suggestion of operation.

20th May. Operation. Local anæsthesia. A small burr hole was made in the region of the right parietal eminence. The dura was pulsating. When it was opened and the spatula passed there was a copious flow of clear fluid from the subdural space. Before the wound was closed the arachnoid was seen to be intact and the brain pulsating freely. A similar procedure was carried out on the left side. Here there was a greater quantity of fluid.

Next morning the patient was feeling "great" as he sat up smoking a cigarette. He left hospital on the fifth day. August 1940. Returned to work.

March 1941. The patient reported that he had been at full work since September 1940 and had been quite free from headaches. In December and January he had, however, "fainted," and had to remain in bed on each occasion for three or four days. His story was suggestive of epileptic attacks, but no corroborative evidence could be obtained.

Case 20.-M. G., aged 30 (a patient of Dr. E. L. Murphy and Mr. Harry Meade, and included here by their courtesy).

In 1935 this patient was thrown off a horse and was rendered unconscious immediately. When admitted to hospital he was found to have a right hemiplegia. He remained unconscious for thirteen days and ultimately made a complete recovery, except for some residual weakness of the right side. In the spring of 1940 his behaviour became erratic, and a tendency to exhibitionism developed. He was reported to have attacks in which he would stand and stare, apparently oblivious of his surroundings. He was euphoric, but had been so for an indefinite time.

July 1940. Neurological examination by Dr. Murphy revealed slight right facial weakness of supranuclear type, definite weakness of the right arm and hand, and some spasticity in the right leg. The patient walked with a right hemiplegic gait. All the tendon jerks were exaggerated on the right side, and the right abdominal reflexes were definitely diminished. There was a positive Babinski reflex on the right. Lumbar puncture. Pressure $190 \mathrm{~mm}$. of water. Fluid normal.

25th July. Operation. Local anæsthesia. Mr. Meade made an opening in the left frontal region. When the dura was opened the brain bulged into the opening and did not pulsate. A spatula was passed under the dura and subdural fluid escaped in a steady flow. After some minutes the brain fell away from the opening and began to pulsate freely. The wound was closed.

The chief result of the operation was a cessation of abnormal behaviour. There was also some improvement in the power of the right hand and leg, and the right facial weakness was no longer noticeable. The plantar response was equivocal. 
March 1941. There has been no retrogression in his condition up to the present.

Case 21.-D. S., religieuse, aged 24, admitted 12th May, 1941, on account of headache and blindness.

In January 1937 the patient slipped on a polished floor; her head hit the floor and she was unconscious for about twenty minutes. She recovered rapidly, but suffered from occasional and severe headaches for the next six months. In April 1938 she unaccountably slept for six hours beyond her usual time of rising, which was $5.30 \mathrm{a} . \mathrm{m}$. In May 1938 menstruation stopped.

In January 1941 she began to walk in her sleep, and continued to do so for two weeks. In this month there was another incident of prolonged sleep. The patient had always been known in the community to have a small appetite, but, despite this, there was a steady gain in weight. For the last few years she had attacks of vomiting lasting on each occasion for about an hour.

Examination revealed slight obesity; hair distribution normal; weight $8 \mathrm{st} .11 \mathrm{lb}$; pulse rate 60 ; blood pressure 120/80. Gynæcological examination revealed no abnormality. Neurological examination was negative, except for visual acuity of $\frac{6}{18}$ in both eyes, and signs of early papillitis. In the radiograms of the skull there was a suggestion of supra-sellar calcification. Exhaustive metabolic examinations were made, but no abnormality was discovered.

2nd February. Both optic discs showed swelling of 2D. 12th February. Visual acuity O.D. $\frac{6}{12}$, O.S. $\frac{6}{18}$. Small scotoma in nasal field of right eye. Papillodema 2D. 26th February. Menstruation returned.

21st April. Patient complained of severe right-sided headaches,

3rd May. Intense " bursting" headache. Patient said she could not see during the attacks, which continued to recur two or three times a day until admission.

14th May. Blind, but pupils reacted briskly to light. It was decided that the apparent swelling of the discs represented an anatomical abnormality, and that the blindness was psychogenic. The supra-sellar calcification noted in earlier radiograms

TABLE 4.-Group $I V$

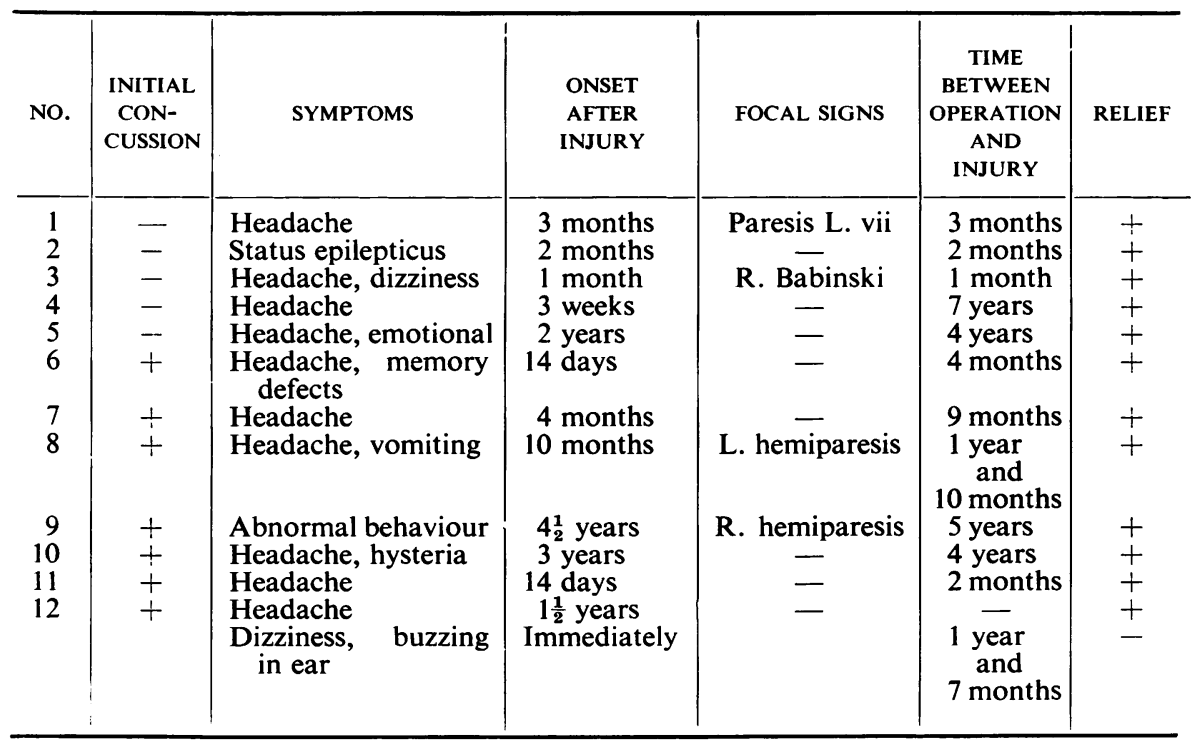


could not be confirmed. Neurological examination was completely negative. The headaches, however, seemed to be genuine and devastating, so ventriculography was advised. An opening was made in the region of the left parietal eminence. The dura was pulsating and there was no tension. Eleven c.cm. of air were injected. The ventricular system appeared normal in the radiograms. It was decided that an operation should be performed at the site of the headache in the right frontal region, partly for psychological reasons and partly because of previous experience of the relation between post-traumatic headache and excess of subdural fluid.

An opening was made just behind the hair line in the right frontal region. When the dura was opened there was a free flow of fluid from the subdural space, the wound, which had a capacity of about $1 \frac{1}{2} \mathrm{c.cm}$., filling up ten times, apart from the amount sucked away at the beginning.

The headache was completely relieved and has not recurred. Inside a week the simplest methods of psychotherapy brought vision back to normal. The appearance of the discs did not change.

These cases are summarized in Table 4.

\section{Comment}

The constancy of an interval between the injury and the onset of symptoms suggests a lesion of slow development, and the fact that the symptoms continued at their initial level suggests that the lesion had become stationary.

In most of the cases removal of the fluid was followed by freer pulsation of the brain and by the relief of symptoms. In a few, the brain remained depressed after removal of the fluid and the symptoms persisted for a short time.

It is important to distinguish between the cases of this group and those of group 3. In this group the patients, with two exceptions, were mentally stable and complained only of headache. The history and operative findings suggest that the brain had either escaped injury altogether or had recovered from injury before the accumulation of fluid had taken place.

In group 3 the lesion was essentially cerebral; in group 4 essentially extracerebral.

\section{Incidence of Subdural Effusions}

The dura mater has been opened and the brain inspected in 63 cases of closed head injury. The operative findings appear in Table 5.

These figures suggest that an excess of subdural fluid is a common lesion in patients who present indications for operation. In this series of cases there is little to suggest that swelling of the brain is usual after injury, or that " unresolved contusion" is of frequent occurrence. It is, of course, impossible to state what conditions obtained in the many patients upon whom operations were not performed. 
TABLE 5

\begin{tabular}{|c|c|c|c|c|}
\hline & & EARLY OPERATION & LATE OPERATION & TOTAL \\
\hline \multirow[t]{2}{*}{$\begin{array}{l}\text { Massive epidural hæmorrhage } \\
\text { Massive subdural hæmorrhage } \\
\text { Intracerebral hæmorrhage } \\
\text { Subdural fluid } \\
\text { Meningeal adhesions } \\
\begin{array}{lcc}\text { Shrunken brain } & \ldots & \ldots \\
\text { Swollen brain } & \ldots & \ldots\end{array}\end{array}$} & $\begin{array}{l}\cdots \\
\cdots \\
\cdots \\
\cdots \\
\cdots \\
\cdots \\
\cdots\end{array}$ & $\begin{array}{l}6 \\
6 \\
1 \\
9 \\
0 \\
2 \\
1\end{array}$ & $\begin{array}{r}0 \\
8 \\
1 \\
23 \\
3 \\
2 \\
1\end{array}$ & $\begin{array}{r}6 \\
14 \\
3 \frac{2}{3} \\
3 \\
4 \\
2\end{array}$ \\
\hline & & 25 & 38 & 63 \\
\hline
\end{tabular}

\section{Relation of Subdural Fluid to Post-traumatic Disturbances}

Twenty-one of the 38 patients upon whom "late" operations were performed had symptoms persisting or beginning a considerable time after the injury.

The operative findings in these "post-traumatic" cases are summarized in Table 6. Cases of epilepsy are not included.

Table 6.-Post-Traumatic Disturbances

\begin{tabular}{|c|c|c|}
\hline SYMPTOMS & LESION FOUND & NO. OF CASES \\
\hline $\begin{array}{l}\text { Headache, dizziness, nervous instability } \\
\text { dating from injury. }\end{array}$ & $\left.\begin{array}{l}\text { Cortical atrophy } \\
\text { Subarachnoid lakes } \\
\text { Subdural fluid }\end{array}\right\}$ & 4 \\
\hline $\begin{array}{l}\text { Headache with or without a definite } \\
\text { nervous symptom, starting after an } \\
\text { interval. }\end{array}$ & $\begin{array}{l}\text { (1) Subdural fluid } \\
\text { (2) Swollen brain (“" Unresolved } \\
\text { contusion," Trotter, 1924). } \\
\text { (3) Shrunken brain }\end{array}$ & $\begin{array}{r}12 \\
1 \\
1\end{array}$ \\
\hline \multirow[t]{2}{*}{ Localized headache with dizziness. } & $\begin{array}{l}\text { Meningeal adhesions (Penfield, } \\
\text { 1936). }\end{array}$ & 3 \\
\hline & & 21 \\
\hline
\end{tabular}

It is clear that post-traumatic disturbances cannot be ascribed to the same lesion in every case.

\section{Origin of the Excess of Subdural Fluid}

No conclusions have been reached regarding the origin and the nature of the fluid. It is usually assumed that the arachnoid membrane is torn at the moment of the accident and that cerebrospinal fluid is forced into the subdural space. Peet (1940) suggests that the tear in the arachnoid membrane is valvular 
in type, so that the fluid cannot return to the subarachnoid space. That a communication does exist between the subarachnoid and subdural spaces in a certain number of post-traumatic cases has been demonstrated by encephalography on many occasions. Penfield and Norcross (1936) stated that in 18 out of 22 cases in which spinal insufflation of air was employed for the relief of post-traumatic headache the air appeared in the subdural space. Lemere and Barnacle (1936) demonstrated air in the subdural space in 20 per cent. of 800 encephalograms, but they do not state whether the air was found more frequently in the traumatic than in the non-traumatic cases.

The fact that a communication exists so frequently suggests that any excessive amount of subdural fluid is derived from the cerebrospinal fluid. On the other hand, an excess of fluid has been found in the subdural space when no communication with the subarachnoid space has been demonstrated.

Another speculation regarding the origin of the fluid may be made. The subdural space normally contains a certain amount of fluid, and it is reasonable to suppose that this amount may be increased under the influence of appropriate stimuli, and that an effusion analogous to that in a pleural, peritoneal, or joint cavity may take place. Such an effusion occurs when infection is introduced into the subdural space. The writer has observed an empyema of the space following a fracture involving an infected frontal sinus; the amount of pus present seemed much greater than any amount which the frontal sinus itself could contain. Courville and Blomquist (1941) have described similar cases. A traumatic effusion from the dura appears to be within the bounds of possibility, and such a conception is not incompatible with the clinical course of the cases reported above.

It is usually difficult to collect sufficient fluid uncontaminated with blood to make accurate estimations of the protein content. In the three cases in which satisfactory estimations were made the protein content was $180,3,500$, and $40 \mathrm{mg}$. per $100 \mathrm{c.cm}$. Although it is always possible that the high amounts of protein were due to an initial mixture of blood and cerebrospinal fluid ("fluid hæmatomas," Munro, 1940), it is also possible that they indicated a true effusion.

\section{Confirmation of the Diagnosis}

Estimations of spinal fluid pressure have not assisted in the diagnosis.

Ventriculography has not revealed the presence of even considerable amounts of fluid in the subdural space. Encephalography has been regarded as a more traumatic performance than the making of twin burr holes. In short, an amount of subdural fluid sufficient to be responsible for the patient's symptoms may escape detection by any method short of opening the dura mater.

It is recognized that observations of a minute area of the meninges and brain yield but a small amount of information, nevertheless such information may be impossible to obtain by less direct methods. 
Operative Procedures

Local anæsthesia is used when possible.

When middle meningeal hæmorrhage is suspected, as it is in most of the early cases, the skull is opened just above the highest part of the temporal crest. The incision in the scalp may be either vertical or horizontal, but it should form a section of whatever incision would be used if a middle meningeal hæmorrhage were found. The length of the incision is about one inch, and it is kept open and dry by a self-retaining mastoid retractor. The bone is opened by Hudson's drill, the conical burr determining the size of the opening in the inner table. The edges of the opening are bevelled with the spherical burr. If extradural hæmorrhage be found, the wound is enlarged and the necessary amount of bone removed towards the base of the skull. If no extradural blood be seen, the dura is opened. Subdural fluid or blood may escape. A curved instrument like Adson's raspatory is passed under the dura, its end keeping close to the bone. Any epidural hæmorrhage pushes the dura inwards, and this displacement can be appreciated when passing the instrument. The pressure of the instrument towards the bone may squeeze epidural blood into the opening. It is safer to search for epidural blood in this way than to pass an instrument between the bone and the dura-a procedure which may start bleeding. If subdural fluid or blood be found in these acute cases it is not necessary to enlarge the opening in the skull. When the brain does not expand, a twisted strip of thin rubber is left as a drain in the subdural space, its other end lying under the scalp. The wound is closed completely. If fluid be found on one side, the whole procedure is repeated on the other side of the skull. In the chronic cases exploration is conveniently carried out through openings made at the sites for ventricular puncture, so that ventriculograms may be made if necessary.

It is important that no "hole in the head" should be left to form the foundation of extravagant claims afterwards. The opening in the skull need be no larger than that obtained with the conical portion of Hudson's drill. A small trephine button can be replaced. Even without attempts at occlusion it is usually difficult to find the site of operation in the course of a few weeks.

\section{Summary}

A subdural effusion has been found in nine out of twenty-five cases of acute head injury. The fluid seemed to act as an expanding lesion of the same order as the massive hæmorrhages.

A subdural effusion has been found in twenty-three out of thirty-eight cases of head injury after the acute stage had passed. The fluid appeared to constitute a passive space-occupying lesion which retarded rather than jeopardized recovery.

The expanding type of effusion was found in two, and the space-occupying type in five, patients who had not suffered from concussion nor given any clinical sign of cerebral damage. 
An attempt has been made to indicate what type of post-traumatic disturbance is amenable to surgery.

\section{REFERENCES}

Courville, C. B., and Blomquist, O. A. (1941). Arch. Surg., 42, 890.

Lemere, F., and Barnacle, C. H. (1936). Arch. Neurol. Psychiat., 35, 990.

Munro, D. (1940). Cranio-cerebral Injuries, London.

Naffziger, H. C. (1924). J. Amer. med. Ass., 82, 1751.

Peet, M. M. (1940). Brock: Injuries of the Skull, Brain and Spinal Cord, London.

Penfield, W. (1923). Amer. J. Dis. Child., 26, 383.

(1924). Anat. Rec., 28, 173.

Penfield, W., and Norcross, N. (1936). Arch. Neurol. Psychiat., 36, 75.

Trotter, W. (1924). Lancet, 1, 935. 